NASA/TM-1998-207411

NASA

,

\title{
Optimality of a Fully Stressed Design
}

Surya N. Patnaik

Ohio Aerospace Institute, Cleveland, Ohio

Dale A. Hopkins

Lewis Research Center, Cleveland, Ohio

National Aeronautics and

Space Administration

Lewis Research Center

May 1998 
Available from

NASA Center for Aerospace Information 7121 Standard Drive Hanover, MD 21076

Price Code: A03
National Technical Information Service 5287 Port Royal Road Springfield, VA 22100 Price Code: A03 


\title{
OPTIMALITY OF A FULLY STRESSED DESIGN
}

\author{
Surya N. Patnaik \\ Ohio Aerospace Institute \\ Cleveland, Ohio 44142 \\ and \\ Dale A. Hopkins \\ National Aeronautics and Space Administration \\ Lewis Research Center \\ Cleveland, Ohio 44135
}

\begin{abstract}
For a truss a fully stressed state is reached when all its members are utilized to their full strength capacity. Historically, engineers considered such a design optimum. But recently this optimality has been questioned, especially since the weight of the structure is not explicitly used in fully stressed design calculations. This paper examines optimality of the fully stressed design (FSD) with analytical and graphical illustrations. Solutions for a set of examples obtained by using the FSD method and optimization methods numerically confirm the optimality of the FSD. The FSD, which can be obtained with a small amount of calculation, can be extended to displacement constraints and to nontruss-type structures.
\end{abstract}

\section{INTRODUCTION}

Researchers are baffled by a conspicuous attribute of the fully stressed design: the good numerical results obtainable with the FSD, even when the merit function, or the weight of the structure, is not used in such calculations. Optimization proponents think that the FSD need not represent the optimum solution since

the good FSD results are considered special cases. Practicing engineers believe that when all the members of a truss (or structure) are utilized to their full strength capacity the design can no longer be improved. They, however, cannot offer a mathematical proof supporting the optimality of the FSD. This dilemma has persisted since the sixties. ${ }^{1-6}$ In this paper an attempt is made to alleviate the confusion. The optimality of the FSD is examined in four sections: the problem is defined; optimality is discussed; numerical examples follow; and discussions and conclusions are presented. 


\section{TRUSS DESIGN PROBLEM}

Consider an $n$-bar truss with $n$ member areas as design variables subjected to $q$ load conditions. A fully stressed state (of FSD) is reached when each member's stress equals allowable strength $\sigma_{0}$. This design can be cast as the following mathematical programming problem: Find $n$ variables $\left(A_{i}\right.$ for $\left.i=1,2, \ldots, n\right)$ to minimize weight $W=\sum_{i=1}^{\mathrm{n}} \rho_{i} 1_{i} A_{i}$ subjected to $n q$ stress constraints

$$
g_{i}=1-\left|\frac{\sigma_{i}}{\sigma_{o}}\right| \quad(i=1,2, \ldots, n q)
$$

The optimum solution-variables $\left(A_{i}^{\text {opt }}\right.$ for $i=1,2, \ldots, n$ ), minimum weight (Wopt), and active constraints $\left(g_{j}^{a c t}=0, j=1,2, \ldots, n\right)-c a n$ be obtained by using one of several optimization methods. ${ }^{7,8}$ In optimization methods, both the weight function and the constraints participate. In the FSD, only the constraints are solved iteratively to obtain the design variables, without any reference to weight. The FSD method weight

(Wfsd) is back-calculated from the areas. That the FSD need not be optimum (i.e., $A_{i}^{\text {opt }} \neq A_{i}^{\text {opt }}$ for $i=1,2, \ldots, n$, and $W f s d \neq W o p t)$ is a popular misconception.

\section{OPTIMALITY OF THE FULLY STRESSED DESIGN}

The Lagrangian functional obtained by adjoining the active constraints to the weight function is used to examine the optimality of the FSD.

$$
\mathscr{L}(\{A\},\{\lambda\})=W(\{A\})+\sum_{\text {active set }} \lambda_{i g i}^{*}(\{A\})
$$


where $\left({ }^{*}\right)$ indicates the active constraints and $\{\lambda\}$ are the multipliers. The variables and the multipliers can be obtained from the stationary condition of the Lagrangian functional with resepct to member areas $\{A\}$ and multipliers as

$$
\begin{gathered}
\nabla W(\{A\})+\sum_{\text {active set }} \lambda_{i} \nabla g_{i}^{*}(\{A\})=\{0\} \\
g_{i}(\{A\})=\{0\} \quad\left(g_{i}^{*} \text { within the active set }\right)
\end{gathered}
$$

Iterative solution to Eqs. (3) and (4) yields the optimum results.

The optimality of the fully stressed design is considered by examining the relation that exists between the design variables and the active constraints in the following three cases.

Case 1: the number of active constraints exceeds the number of design variables

Case 2: the number of active constraints equals the number of design variables

Case 3: the number of active constraints is fewer than the number of design variables A three-bar truss subjected to two load conditions (see Fig. 1(a)), with three design variables, six stress constraints, and weight as the merit function, is used for illustration of the three cases.

Case 1: Number of Active Constraints Exceeds the Number of Design Variables

Geometrical_solution.-Consider an optimum solution with $n$ variables and $(n+v)$ active constraints. The optimal solution is at the intersection of any $n$ out of the $(n+v)$ active constraints. The remaining $v$ are follower constraints passing through the optimal point. For the truss with three design variables, assume an optimal design with four active constraints, $g_{1}, g_{3}, g_{5}$, and $g_{6}$ (see Fig. 1(b)). Three constraints $\left(g_{3}, g_{5}\right.$, and $\left.g_{6}\right)$ are sufficient to establish the optimal point. The follower constraint $\left(g_{1}\right)$ can be neglected without any consequence. From a geometrical consideration, the inclusion of a maximum of $n$ active constraints is sufficient to establish the optimal design. The weight function is not essential when $v>0$ or the number of active constraints exceeds the number of design variables. 
Analytical solution.-The $(2 n+v)$ unknowns (being $n$ design variables and $(n+v)$ multipliers) can be determined as the solution to Eqs. (3) and (4). A simple strategy, however, is to solve for the $n$ design variables from any $n$ of $(n+v)$ constraint functions given by Eq. (4), which does not contain the Lagragian multipliers. Values for the multipliers and the weight function can be back-calculated. In other words, when the number of active constraints exceeds the number of design variables, the optimum can be obtained from the solution of a set of $n$ active constraints. This procedure is adopted in the stress-ratio-based fully stressed design method. The solution thus obtained is optimum because it satisfies Eqs. (3) and (4).

Case 2: Number of Active Constraints Equals the Number of Design Variables

An optimal solution with $n$ variables and $n$ active constraints, by definition, represents a fully stressed design. The stationary condition of the Lagrangian (Eqs. (3) and (4)) represents $2 n$ equations in $2 n$ unknowns. The uncoupled Eq. (4), being $n$ constraint equations, can be solved for the $n$ design variables. The $n$ multipliers and optimum weight can be back-calculated from the design variables. For the three-bar truss, the solution of three constraints will yield the design variables. The optimum weight and the multipliers can be backcalculated from Eqs. (1) and (3) respectively.

When the number of active constraints equals or exceeds the number of design variables, the solution of the active constraints (i.e., Eq. (4)) provides the design variables. The design thus obtained is both fully stressed and optimum.

\section{Case 3: Fewer Active Constraints Than Design Variables}

An optimum solution with fewer active constraints than design variables is not a fully stressed design. For the three-bar truss, assume two active constraints $\left(g_{1}\right.$ and $\left.g_{2}\right)$ given by Eq. (4). The two constraint equations are expressed in terms of three unknown design variables. Although Eq. (4) is independent of Lagrangian multipliers, it does not have sufficient quantity for a solution of the three design variables. Thus, both Eqs. (3) and (4), which are coupled in variables, multipliers, and weight gradient, must be solved simultaneously to generate the optimum solution. The gradient of the weight function and the multipliers are 
required to calculate the design variables. In other words, only when the number of active constraints is fewer than the number of design variables do both the constraints and the weight function participate. Mathematical programming methods address this situation in particular. Practical truss design, however, more frequently falls under Cases 1 and 2. Academic truss examples satisfying the Case 3 condition can be easily obtained by changing the strength, Young's modulus, and certain other geometrical parameters. 9

\section{Design of a Truss Under a Single Load Condition}

For an indeterminate truss under a single load condition, a full stress state may not be achievable because of the compatibility condition. 5,7,10 Take, for example, an $n$-bar truss with $r$ redundant members. If its FSD is attempted without restricting the lower bound for the member areas, then the design will degenerate to a determinate structure that, of course, will be fully stressed and optimum. If, however, a minimum bound $A^{\mathrm{min}}$ is specified for member areas, the resulting design will have $(n-r)$ fully stressed members with $(n-r)$ active stress constraints and $r$ member areas that reach the minimum bounds of $A^{\min }$. These properties, from an analytical viewpoint, become equivalent to $n$ active constraints consisting of $(n-r)$ stress constraints and $r$ lower bound side constraints. Since there are $n$ design variables, this example falls under Case 2 . In other words, the fully stressed design of a truss under a single load also represents the optimum design.

A fully stressed design state can be defined in terms of two indices, Indexstress and Index all:

$$
\begin{gathered}
\text { Index }^{\text {stress }}=\frac{(\text { number of active stress constraints })}{(\text { number of independent design variables })} \\
\text { Index }^{\text {all }}=\frac{(\text { number of active stress constraints }+ \text { number of active bounds })}{\text { (number of independent design variables })} \\
\text { Index }=\text { maximum }\left(\text { Index }^{\text {stress }}, \text { Index }^{\text {all }}\right)
\end{gathered}
$$

For analytical purposes, a fully stressed state is reached when the Index $\geq 1$. 


\section{NUMERICAL EXAMPLES}

The examples are separated into a first example and a group of problems. The first example, with several subcases, examines the role of the weight function when the number of active constraints exceeds or equals the number of design variables (or Cases 1 and 2). The second group of examples compares stress-ratiobased FSD's with their optimum designs obtained using design optimization methods. Two optimizers, SUMT (Sequential Unconstrained Minimization Technique) and IMSL (i.e., the Sequence of Quadratic Programming technique of IMSL) are used to solve examples in group 2. The figures and descriptions for the examples are not given here but can be found in Refs. 7 and 8 . All the examples were solved in a controlled environment on the NASA Lewis Cray Y-MP computer.

\section{Example 1}

A three-bar truss (see Fig.1(a)) is used to illustrate that the weight function does not influence the optimum design when the number of active constraints equal or exceed the number of design variables. The truss is subjected to two load conditions and has a total of six stress constraints, three per load condition. The optimum solution for an aluminum truss with equal weight densities of $0.1 \mathrm{lb} / \mathrm{in} .^{3}$ for its three bars was obtained by using several optimization algorithms. The optimum solution for the problem consists of optimum weight $W^{o p t}=133 \mathrm{lb}$; design variable $A^{o p t}=(3.29,3.99,3.32)$ in.2; and four active stress constraints $\left(g_{1}, g_{3}\right.$, $g_{5}$, and $\left.g_{6}\right)$.

Fully stressed design.- The stress-ratio-based FSD produced a solution that is identical to the optimum design obtained by using optimization methods. The weight coefficients were changed over a wide range, from $0.1 \mathrm{lb} / \mathrm{in}^{3}$ for aluminum to $300 \mathrm{lb} / \mathrm{in}^{3}$ for a fictitious material. The design and active constraints obtained by FSD remained the same since the weight does not participate in the calculation. The FSD weight, however, was back-calculated and is shown in table 1 .

SUMT optimizer.-Solutions for five different sets for weights of the bars were attempted by SUMT (see table 1). The SUMT optimizer converged to the optimum solution for the first four cases, producing the 
correct optimum weight and an identical set of four active constraints. For the fifth case, SUMT converged to an eccentric local optimum design with two, instead of four, active constraints.

IMSL optimizer.-This optimizer produced correct solutions for the last four cases. For the first case, no active constraints were produced and the IMSL solution was unsatisfactory.

Table 1 also shows solutions obtained with other optimization methods. The FSD method provided successful solutions for all five cases. The success rate for optimization methods varied.

\section{Example Set 2}

Nine examples were solved by using FSD along with SUMT and IMSL optimizers. The normalized results with respect to the FSD answers are depicted in table 2 .

Consider the 25-bar truss, referred to as BAR25 in table 2. It is subjected to two load conditions. Its 25 areas are linked to obtain 8 independent variables. Since at optimum, 11 stress constraints are active, a fully stressed state has been reached. The FSD, IMSL, and SUMT methods produced identical optimum solutions for the example with different CPU times. Optimizers IMSL and SUMT were, respectively, 10 and 18.5 times more expensive than the FSD method. Solutions to the other eight problems followed the pattern of the 25-bar truss, with minor variations.

\section{DISCUSSION}

For a truss, if a fully stressed state can be reached (i.e., the number of active constraints exceeds the number of design variables), then such a design can be handled satisfactorily with the stress-ratio-based FSD method. Optimization techniques for such problems can be computationally expensive and unnecessary.

In special circumstances a practical structural design may be associated with fewer active constraints than design variables. Such a design is likely to represent an overdesign condition, which can be alleviated by relaxing some of the nonactive constraints. If, however, there are fewer active constraints than design variables, then the design is not fully stressed; here, nonlinear programming optimization methods can be 
useful. For such problems the stress-ratio-based design can differ from the optimum design, especially when weight densities for truss members are different.

When the fully stressed design is extended to include displacement constraints, it is called a fully utilized design (FUD). The FUD, which can produce overdesign conditions, has been modified to obtain a modified fully utilized design method that produces a satisfactory design for stress and displacement constraints. ${ }^{10,11}$ The FUD method has been extended in Ref. 12 to nontruss-type structures for frequency constraints.

The authors recognize the importance of nonlinear mathematical programming technique-based structural design optimization. ${ }^{3}$ There are, however, design situations wherein simpler design methods such as the fully stressed design method can produce acceptable practical designs. Such situations can be identified when the number of active constraints equals or exceeds the number of design variables.

\section{CONCLUSIONS}

A fully stressed design is optimum when a full stress state can be achieved. At optimum, when the number of active constraints equals or exceeds the number of design variables, then such a design becomes a fully stressed design. Such a design can be obtained through a stress-ratio algorithm or by solving the constraints without any consideration to the weight function. The stress-ratio algorithm can produce a fully stressed design in a small fraction of the calculation time required by the design optimization methods. The fully stressed design method may have the potential for extension to nontruss-type structures and nonstress constraints. Design optimzation techniques may have to be used when the number of active constraints is fewer than the number of design variables.

\section{REFERENCES}

1. R. H. Gallagher and O. C. Zienkiewicz, Optimum Structural Design, John Wiley \& Sons, London, 1973.

2. T. P. Kicher, 'Optimum design-minimum weight versus fully stressed', J. structural div., ASCE, 92, 265-279, (1966). 
3. L. A. Schmit, 'Structural design by systematic synthesis', Proceedings, 2nd Conference on Electronic Computation, ASCE, 105-132 (1960).

4. R. Razani, 'Behavior of fully stressed design of structures and its relationship to minimum weight design', AIAA J., 3, 12, 2262-2268 (1965).

5. P. Dayaratnam and S. N. Patnaik, 'Feasibility of fully stressed design', AIAA J, 7, 773-774 (1969).

6. S. N. Patnaik and P. Dayaratnam, 'Behavior and design of pin connected structures', Int. J. Numer. Meth. Eng., 2, 579-595, (1970).

7. J. D. Guptill et al., CometBoards Users Manual Release 1.01, NASA TM-4537, 1995.

8. S. N. Patnaik et al., 'Comparative evaluation of different optimization algorithms for structural design applications', Int. J. Numer. Meth. Eng., 39, 1761-1774 (1996).

9. L. Berke and N. S. Khot, Use of Optimality Criteria Methods for Large Scale Systems, AGARD LS-70, $1-29,1974$.

10. S. N. Patnaik, 'Behavior of trusses with stress and displacement constraints', Compt. Struct., 22, 619-623 (1986).

11. S. N. Patnaik et al., 'Modified fully utilized design (MFUD) method for stress and displacement constraints', Int. J. Numer. Meth. Eng. (1997).

12. S. N. Patnaik and S. Yadagiri, 'Design for frequency by integrated force method', Comp. Methods Appl. Mech. Eng. 16, 213-230 (1978). 
Table 1.-Optimum Designs of Three-Bar Truss With Different Materials

[Number of active constraints exceed number of design variables.]

\begin{tabular}{|c|c|c|c|c|c|c|c|c|}
\hline Method & \multicolumn{3}{|c|}{$\begin{array}{l}\text { Cost } \\
\text { coefficients }\end{array}$} & \multicolumn{3}{|c|}{ Member areas } & $\begin{array}{c}\text { Active } \\
\text { constraints }\end{array}$ & $\begin{array}{l}\text { Optimum } \\
\text { weight, lb }\end{array}$ \\
\hline FSD & $\begin{array}{c}0.1 \\
3 \\
6 \\
16 \\
1\end{array}$ & $\begin{array}{c}0.1 \\
6 \\
12 \\
13 \\
200\end{array}$ & $\begin{array}{r}0.1 \\
8 \\
18 \\
25 \\
300\end{array}$ & $\left.\right|_{\downarrow} ^{3.30}$ & $\begin{array}{c}3.99 \\
\mid\end{array}$ & 3.32 & $\mathbf{g}_{1, \mathbf{g}}, \mathbf{g}_{5}, \mathrm{~g}_{6}$ & $\begin{array}{l}1.33 \times 10^{8} \\
7.53 \times 10^{\beta} \\
1.60 \times 10^{4} \\
2.43 \times 10^{4} \\
2.20 \times 10^{\circ}\end{array}$ \\
\hline SUMT & $\begin{array}{c}0.1 \\
3 \\
6 \\
16 \\
1\end{array}$ & $\begin{array}{l}0.1 \\
6 \\
12 \\
13 \\
200\end{array}$ & $\begin{array}{r}0.1 \\
8 \\
18 \\
25 \\
300\end{array}$ & $\begin{array}{r}3.291 \\
3.299 \\
3.299 \\
3.298 \\
67.068\end{array}$ & $\begin{array}{l}3.986 \\
3.998 \\
3.997 \\
3.998 \\
9.111\end{array}$ & \begin{tabular}{|}
3.323 \\
3 \\
299 \\
3. \\
298
\end{tabular} & $\mathrm{~g}_{1}, \mathrm{~g}_{3}, \mathrm{gs}_{5}, \mathrm{~g}_{6}$ & $\begin{array}{l}1.33 \times 10^{2} \\
7.53 \times 10^{3} \\
1.59 \times 10^{4} \\
2.43 \times 10^{4} \\
1.92 \times 10^{5}\end{array}$ \\
\hline ISML & $\begin{array}{c}0.1 \\
3 \\
6 \\
16 \\
1\end{array}$ & $\begin{array}{c}0.1 \\
6 \\
12 \\
13 \\
200\end{array}$ & $\begin{array}{r}0.1 \\
8 \\
18 \\
25 \\
300\end{array}$ & $\begin{array}{l}1.000 \\
3.299 \\
\downarrow\end{array}$ & $\begin{array}{c}1.000 \\
4.000 \\
\downarrow\end{array}$ & $\begin{array}{c}1.000 \\
3.299 \\
\mid\end{array}$ & $\prod^{\text {(a) }}$ & $\begin{array}{l}3.83 \times 10^{1} \\
7.53 \times 10^{9} \\
1.60 \times 10^{4} \\
2.43 \times 10^{4} \\
2.20 \times 10^{\circ}\end{array}$ \\
\hline OPTM1 & $\begin{array}{c}0.1 \\
3 \\
6 \\
16 \\
1\end{array}$ & $\begin{array}{c}0.1 \\
6 \\
12 \\
13 \\
200\end{array}$ & $\begin{array}{r}0.1 \\
8 \\
18 \\
25 \\
300\end{array}$ & $\begin{array}{l}3.313 \\
3.309 \\
3.309 \\
3.308 \\
3.300\end{array}$ & $\begin{array}{l}3.971 \\
3.963 \\
3.962 \\
3.961 \\
3.967\end{array}$ & \begin{tabular}{l|}
3.323 \\
3.3 \\
34 \\
3.3 \\
35
\end{tabular} & $\mathrm{~g}_{1}, \mathrm{~g}_{3}, \mathrm{~g}_{5}, \mathrm{~g}_{6}$ & $\begin{array}{l}1.33 \times 10^{\circ} \\
7.55 \times 10^{\beta} \\
1.60 \times 10^{4} \\
2.44 \times 10^{4} \\
2.21 \times 10^{\circ}\end{array}$ \\
\hline SQP & $\begin{array}{c}0.1 \\
3 \\
6 \\
16 \\
1\end{array}$ & $\begin{array}{c}0.1 \\
6 \\
12 \\
13 \\
200\end{array}$ & $\begin{array}{r}0.1 \\
8 \\
18 \\
25 \\
300\end{array}$ & $\begin{array}{l}2.335 \\
2.334 \\
2.334 \\
2.335 \\
2.335\end{array}$ & $\begin{array}{c}2.503 \\
\mid\end{array}$ & $\begin{array}{l}2.505 \\
1 . \mid\end{array}$ & (a) & $\begin{array}{l}9.35 \times 10^{1} \\
5.32 \times 10^{3} \\
1.14 \times 10^{4} \\
1.74 \times 10^{4} \\
1.57 \times 10^{5}\end{array}$ \\
\hline OPTM2 & $\begin{array}{c}0.1 \\
3 \\
6 \\
16 \\
1\end{array}$ & $\begin{array}{c}0.1 \\
6 \\
12 \\
13 \\
200\end{array}$ & $\begin{array}{r}0.1 \\
8 \\
18 \\
25 \\
300\end{array}$ & $\begin{array}{l}3.199 \\
3.501 \\
3.635 \\
3.657 \\
3.684\end{array}$ & $\begin{array}{l}2.556 \\
2.402 \\
2.353 \\
2.316 \\
2.336\end{array}$ & $\begin{array}{l}5.102 \\
4.682 \\
4.563 \\
4.467 \\
4.512\end{array}$ & $\begin{array}{c}\mathrm{g}_{1}, \mathrm{~g}_{5} \\
\text { (a) } \\
\mathrm{g}_{6} \\
\mathrm{~g}_{6} \\
\mathrm{~g}_{6}\end{array}$ & $\begin{array}{l}1.42 \times 10^{2} \\
8.22 \times 10^{8} \\
1.75 \times 10^{4} \\
2.71 \times 10^{4} \\
2.39 \times 10^{5}\end{array}$ \\
\hline
\end{tabular}


Table 2.-Performance of Fully Stressed Design Versus Optimization Methods

\begin{tabular}{|c|c|c|c|c|c|c|c|c|c|}
\hline Problem & $\begin{array}{c}\text { Load } \\
\text { condition }\end{array}$ & $\begin{array}{l}\text { Independent } \\
\text { design } \\
\text { variables }\end{array}$ & $\begin{array}{l}\text { Design } \\
\text { method }\end{array}$ & $\begin{array}{l}\text { Normalized } \\
\text { weight }\end{array}$ & $\begin{array}{l}\text { Number of } \\
\text { active } \\
\text { stress } \\
\text { constraints }\end{array}$ & $\begin{array}{l}\text { Number of } \\
\text { active side } \\
\text { constraints }\end{array}$ & Indexall & Index stress & $\begin{array}{l}\text { Normalized } \\
\text { CPU time }\end{array}$ \\
\hline BAR3 & 1 & 3 & $\begin{array}{l}\text { FSD } \\
\text { IMSL } \\
\text { SUMT }\end{array}$ & $\begin{array}{l}1.000 \\
1.000 \\
1.000\end{array}$ & $\begin{array}{l}2 \\
2 \\
2\end{array}$ & $\begin{array}{l}1 \\
1 \\
1\end{array}$ & $\begin{array}{l}1.0 \\
1.0 \\
1.0\end{array}$ & $\begin{array}{r}0.600 \\
.600 \\
.600\end{array}$ & $\begin{array}{l}1.000 \\
1.596 \\
6.263\end{array}$ \\
\hline BAR5 & 2 & 5 & $\begin{array}{l}\text { FSD } \\
\text { IMSL } \\
\text { SUMT }\end{array}$ & $\begin{array}{l}1.000 \\
1.000 \\
1.000\end{array}$ & $\begin{array}{l}7 \\
7 \\
8\end{array}$ & $\begin{array}{l}0 \\
0 \\
0\end{array}$ & $\begin{array}{l}1.4 \\
1.4 \\
1.6\end{array}$ & $\begin{array}{l}1.400 \\
1.400 \\
1.600\end{array}$ & $\begin{array}{l}1.000 \\
.527 \\
1.288\end{array}$ \\
\hline BAR10 & 1 & 10 & $\begin{array}{l}\text { FSD } \\
\text { IMSL } \\
\text { SUMT }\end{array}$ & $\begin{array}{l}1.000 \\
1.000 \\
1.001\end{array}$ & $\begin{array}{l}6 \\
6 \\
6\end{array}$ & $\begin{array}{l}4 \\
4 \\
4\end{array}$ & $\begin{array}{l}1.0 \\
1.0 \\
1.0\end{array}$ & $\begin{array}{r}0.600 \\
.600 \\
.600\end{array}$ & $\begin{array}{l}1.000 \\
1.362 \\
2.859\end{array}$ \\
\hline BAR25 & 2 & 8 & $\begin{array}{l}\text { FSD } \\
\text { IMSL } \\
\text { SUMT }\end{array}$ & $\begin{array}{l}1.000 \\
1.000 \\
1.001\end{array}$ & $\begin{array}{l}11 \\
11 \\
11\end{array}$ & $\begin{array}{l}3 \\
3 \\
3\end{array}$ & $\begin{array}{l}1.75 \\
1.75 \\
1.75\end{array}$ & $\begin{array}{l}1.375 \\
1.375 \\
1.375\end{array}$ & $\begin{array}{c}1.000 \\
8.688 \\
14.213\end{array}$ \\
\hline DOME & 1 & 12 & $\begin{array}{l}\text { FSD } \\
\text { IMSL } \\
\text { SUMT }\end{array}$ & $\begin{array}{r}1.000 \\
.983 \\
.984\end{array}$ & $\begin{array}{l}188 \\
192 \\
192\end{array}$ & $\begin{array}{l}5 \\
5 \\
4\end{array}$ & $\begin{array}{l}16.08 \\
16.42 \\
16.33\end{array}$ & $\begin{array}{l}15.667 \\
16.000 \\
16.000\end{array}$ & $\begin{array}{r}1.000 \\
.743 \\
.740\end{array}$ \\
\hline RING_A & 3 & 25 & $\begin{array}{l}\text { FSD } \\
\text { IMSL } \\
\text { SUMT }\end{array}$ & $\begin{array}{r}1.000 \\
.999 \\
1.000\end{array}$ & $\begin{array}{l}40 \\
38 \\
38\end{array}$ & $\begin{array}{l}0 \\
0 \\
0\end{array}$ & $\begin{array}{l}1.60 \\
1.52 \\
1.52\end{array}$ & $\begin{array}{l}1.600 \\
1.520 \\
1.520\end{array}$ & $\begin{array}{r}1.000 \\
5.476 \\
13.101\end{array}$ \\
\hline RING_B & 1 & 60 & $\begin{array}{l}\text { FSD } \\
\text { IMSL } \\
\text { SUMT }\end{array}$ & $\begin{array}{l}1.000 \\
1.000 \\
1.003\end{array}$ & $\begin{array}{l}52 \\
52 \\
52\end{array}$ & $\begin{array}{r}16 \\
16 \\
8\end{array}$ & $\begin{array}{l}1.133 \\
1.133 \\
1.0\end{array}$ & $\begin{array}{r}0.867 \\
.867 \\
.867\end{array}$ & $\begin{array}{l}1.000 \\
2.882 \\
5.569\end{array}$ \\
\hline TOWER_A & 1 & 252 & $\begin{array}{l}\text { FSD } \\
\text { IMSL } \\
\text { SUMT }\end{array}$ & $\begin{array}{c}1.000 \\
.999 \\
1.000\end{array}$ & $\begin{array}{l}117 \\
117 \\
117\end{array}$ & $\begin{array}{l}135 \\
131 \\
139\end{array}$ & $\begin{array}{l}1.0 \\
.984 \\
1.016\end{array}$ & $\begin{array}{r}0.464 \\
.520 \\
.551\end{array}$ & $\begin{array}{r}1.000 \\
57.249 \\
81.442\end{array}$ \\
\hline TOWER_B & 2 & 252 & $\begin{array}{l}\text { FSD } \\
\text { IMSL } \\
\text { SUMT }\end{array}$ & $\begin{array}{l}1.000 \\
1.000 \\
1.000\end{array}$ & $\begin{array}{l}165 \\
165 \\
165\end{array}$ & $\begin{array}{l}97 \\
98 \\
99\end{array}$ & $\begin{array}{l}1.040 \\
1.044 \\
1.048\end{array}$ & $\begin{array}{r}0.655 \\
.655 \\
.655\end{array}$ & $\begin{array}{r}1.000 \\
48.031 \\
59.557\end{array}$ \\
\hline
\end{tabular}




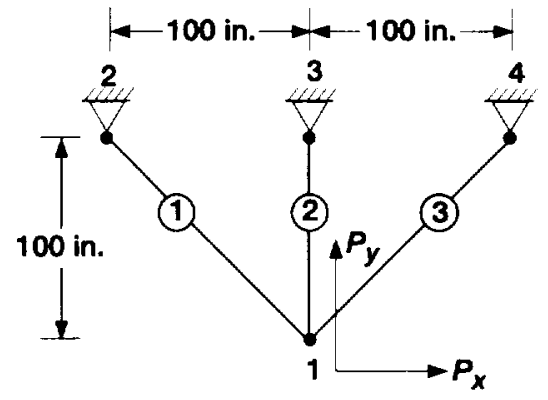

\begin{tabular}{|c|c|c|c|}
\hline Load & \multicolumn{3}{|c|}{ Load components, kips } \\
\cline { 2 - 4 } & Node & $P_{x}$ & $P_{y}$ \\
\hline I & 1 & 70.0 & 0.0 \\
II & 1 & -35.0 & -95.0 \\
\hline
\end{tabular}

(a) The structure and loads.

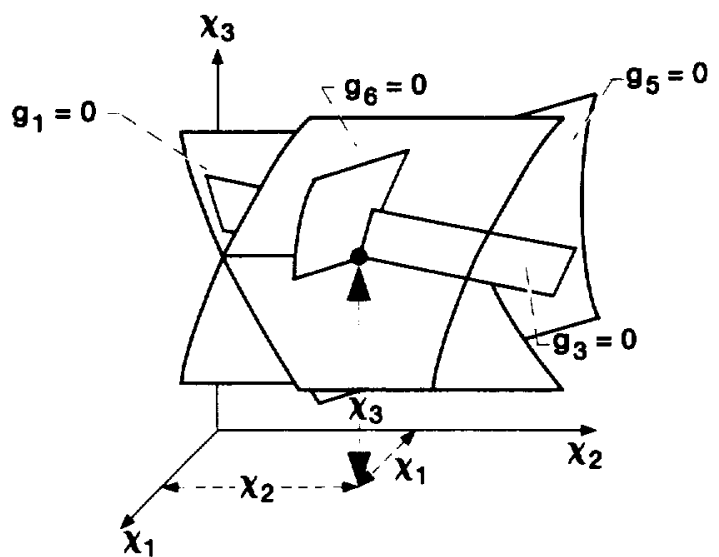

(b) The constraint space.

Figure 1.-The three-bar truss. 



\begin{tabular}{|c|c|c|c|c|}
\hline \multicolumn{3}{|c|}{ REPORT DOCUMENTATION PAGE } & \multicolumn{2}{|r|}{$\begin{array}{l}\text { Form Approved } \\
\text { OMB No. } 0704-0188\end{array}$} \\
\hline \multicolumn{5}{|c|}{ 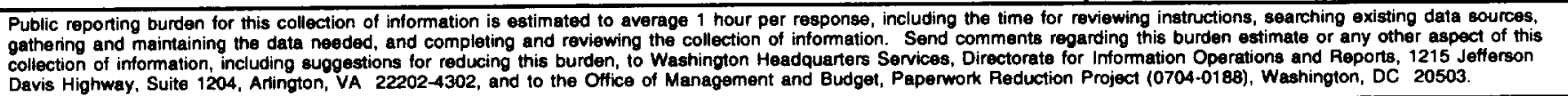 } \\
\hline 1. AGENCY USE ONLY (Leave blanK) & $\begin{array}{r}\text { 2. REPOAT DATE } \\
\text { May } 1998\end{array}$ & \multicolumn{3}{|c|}{$\begin{array}{l}\text { 3. AEPORT TYPE AND DATES COVERED } \\
\text { Technical Memorandum }\end{array}$} \\
\hline \multicolumn{3}{|c|}{$\begin{array}{l}\text { 4. TITLE AND SUBTTLE } \\
\text { Optimality of a Fully Stressed Design }\end{array}$} & \multicolumn{2}{|c|}{ 5. FUNDING NUMBERS } \\
\hline \multicolumn{3}{|c|}{$\begin{array}{l}\text { 6. AUTHOR(S) } \\
\text { Surya N. Patnaik and Dale A. Hopkins }\end{array}$} & \multicolumn{2}{|c|}{ WU $-505-53-5 B-00$} \\
\hline \multicolumn{3}{|c|}{$\begin{array}{l}\text { 7. PERFORMING ORGANIZATION NAME(S) AND ADDRESS(ES) } \\
\text { National Aeronautics and Space Administration } \\
\text { Lewis Research Center } \\
\text { Cleveland, Ohio } 44135-3191\end{array}$} & \multicolumn{2}{|c|}{$\begin{array}{l}\text { 8. PERFORMING ORGANIZATION } \\
\text { REPORT NUMBER } \\
\text { E-10284-1 }\end{array}$} \\
\hline \multicolumn{3}{|c|}{$\begin{array}{l}\text { 9. SPONSORINGMONITORING AGENCY NAME(S) AND ADDRESS(ES) } \\
\text { National Aeronautics and Space Administration } \\
\text { Washington, DC 20546-0001 }\end{array}$} & \multicolumn{2}{|c|}{$\begin{array}{l}\text { 10. SPONSORINGMONTORING } \\
\text { AGENCY REPORT NUMBER } \\
\text { NASA TM-1998-207411 }\end{array}$} \\
\hline \multirow{2}{*}{\multicolumn{5}{|c|}{$\begin{array}{l}\text { 11. SUPPLEMENTARY NOTES } \\
\text { Responsible person, Surya N. Patnaik, organization code 5210, (216) 433-5916. }\end{array}$}} \\
\hline & & & & \\
\hline \multirow{2}{*}{\multicolumn{3}{|c|}{$\begin{array}{l}\text { 12a. DISTRIBUTIONAVAILABILTYY STATEMENT } \\
\text { Unclassified - Unlimited } \\
\text { Subject Category: } 39 \\
\text { This publication is available from the NASA Center for AeroSpace Information, (301) 621-0390. }\end{array}$}} & \multirow{2}{*}{\multicolumn{2}{|c|}{ 12b. DISTRIBUTION CODE }} \\
\hline & & & & \\
\hline \multicolumn{5}{|c|}{$\begin{array}{l}\text { 13. ABSTRACT (Maximum } 200 \text { worda) } \\
\text { For a truss a fully stressed state is reached and when all its members are utilized to their full strength capacity. Histori- } \\
\text { cally, engineers considered such a design optimum. But recently this optimality has been questioned, especially since } \\
\text { the weight of the structure is not explicitly used in fully stressed design calculations. This paper examines optimality of } \\
\text { the full stressed design (FSD) with analytical and graphical illustrations. Solutions for a set of examples obtained by } \\
\text { using the FSD method and optimization methods numerically confirm the optimality of the FSD. The FSD, which can } \\
\text { be obtained with a small amount of calculation, can be extended to displacement contstraints and to nontruss-type } \\
\text { structures. }\end{array}$} \\
\hline \multicolumn{3}{|l|}{ 14. SUBJECT TERMS } & & $\begin{array}{l}\text { 15. NUMBER OF PAGES } \\
18\end{array}$ \\
\hline \multirow{2}{*}{\multicolumn{3}{|c|}{ Truss; Design; Fully stressed; Optimality; Lagrangian }} & & \begin{tabular}{|l|} 
16. PRICE CODE \\
\end{tabular} \\
\hline & & & & $\frac{\mathrm{A} 03}{2}$ \\
\hline $\begin{array}{l}\text { 17. SECUATY CLASSIFICATION } \\
\text { OF REPORT }\end{array}$ & $\begin{array}{l}\text { 18. SECURTTY CLASSIFICATION } \\
\text { OF THIS PAGE }\end{array}$ & $\begin{array}{l}\text { 19. SECUAITY CLASSIFC } \\
\text { OF ABSTRACT }\end{array}$ & ATION & 20. LIMITATION OF ABSTRACT \\
\hline Unclassified & Unclassified & Unclassified & & \\
\hline NSN 7540-01-280-5500 & & & & $\begin{array}{l}\text { andard Form } 298 \text { (Rev. 2-89) } \\
\text { escribed by ANSI Std. Z39-18 }\end{array}$ \\
\hline
\end{tabular}

